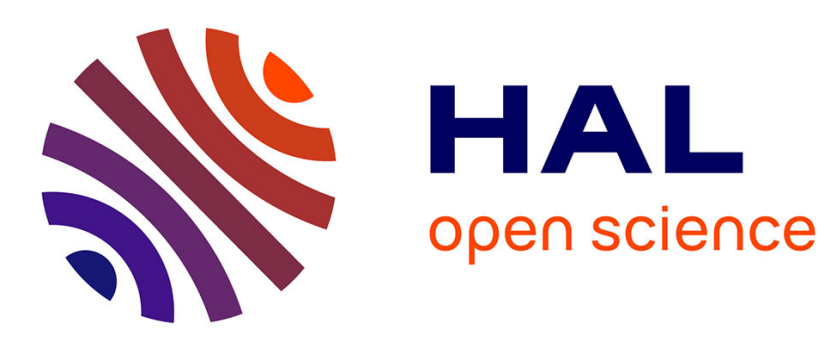

\title{
Deep eutectic solvent-based headspace single-drop microextraction for the quantification of terpenes in spices
}

Zélie Triaux, Hugues Petitjean, Eric Marchioni, Maria Yu Boltoeva, Christophe Marcic

\section{To cite this version:}

Zélie Triaux, Hugues Petitjean, Eric Marchioni, Maria Yu Boltoeva, Christophe Marcic. Deep eutectic solvent-based headspace single-drop microextraction for the quantification of terpenes in spices. Analytical and Bioanalytical Chemistry, 2020, 412 (4), pp.933-948. 10.1007/s00216-019-02317-9 . hal-02919757

\section{HAL Id: hal-02919757 \\ https://hal.science/hal-02919757}

Submitted on 7 Dec 2020

HAL is a multi-disciplinary open access archive for the deposit and dissemination of scientific research documents, whether they are published or not. The documents may come from teaching and research institutions in France or abroad, or from public or private research centers.
L'archive ouverte pluridisciplinaire HAL, est destinée au dépôt et à la diffusion de documents scientifiques de niveau recherche, publiés ou non, émanant des établissements d'enseignement et de recherche français ou étrangers, des laboratoires publics ou privés. 
Deep eutectic solvents-based headspace single drop microextraction for the quantification of terpenes in spices

Zélie Triaux ${ }^{\mathrm{a}, \mathrm{b}}$, Hugues Petitjean ${ }^{\mathrm{b}}$, Eric Marchioni ${ }^{\mathrm{a}}$, Maria Boltoeva ${ }^{\mathrm{a}}$, Christophe Marcic ${ }^{\mathrm{a},{ }^{*}}$

${ }^{\text {a } U n i v e r s i t e ́ ~ d e ~ S t r a s b o u r g, ~ C N R S, ~ I P H C ~ U M R ~ 7178, ~ F-67000 ~ S t r a s b o u r g, ~ F r a n c e . ~}$

${ }^{\mathrm{b}}$ Benephyt, 16 rue d'Austerlitz, 67000 Strasbourg, France.

"Corresponding Author:

Christophe Marcic, Tel.: +33 3688541 60, Email: christophe.marcic@ unistra.fr 


\begin{abstract}
Deep eutectic solvents (DESs) were investigating as extracting solvent for headspace single drop microextraction (HS-SDME). The extraction efficiency of ten DESs mainly composed of tetrabutylammonium bromide $\left(\mathrm{N}_{4444} \mathrm{Br}\right)$ and long chain alcohols was evaluated for the extraction of terpenes from six spices (cinnamon, cumin, fennel, clove, thyme and nutmeg). The DES composed of $\mathrm{N}_{4444} \mathrm{Br}$ and dodecanol at a molar ratio of 1:2 showed the highest extraction efficiency and was selected to conduct the extractions of terpenes in the rest of the study. HS-SDME was optimized by design of experiments. Only two parameters from the four studied showed a significant influence on the efficiency of the method: the extraction time and the extraction temperature. The optimal extraction conditions were determined by response surface methodology. All extracts were analyzed by gas chromatography coupled to mass spectrometry (GC-MS). More than 40 terpenes were extracted and identified in nutmeg, the richest extract in terpenes in this study. Quantitative analysis based on 29 standards was conducted for each extract. Good linearity was obtained for all standards $\left(R^{2}>0.99\right)$ in the interval of 1 to $500 \mu \mathrm{g} / \mathrm{g}$. Limits of quantification ranged from $0.47 \mu \mathrm{g} / \mathrm{g}$ (borneol) to 86.40 $\mu \mathrm{g} / \mathrm{g}$ ( $\alpha$-farnesene) with more than half of the values under $2 \mu \mathrm{g} / \mathrm{g}$. HS-SDME is simple, rapid and cheap compared to conventional extraction methods. The use of DESs makes this extraction method "greener" and it was shown that DESs can be suitable solvents for the extraction of bioactive compounds from plants.
\end{abstract}

\title{
Keywords
}

Deep eutectic solvents; microextraction; chemometric; terpenes, GC-MS. 


\section{Introduction}

The search of natural products for drug discovery has become a keen interest among researchers in the past few decades [1]. Natural products and their bioactive compounds have been used from ancient times for the treatment of various diseases and their potential to substitute chemical drugs has been widely studied [2]. Natural bioactive components mostly come from secondary metabolites. Compared to primary metabolites essential to physiological processes (growth, development and reproduction) of a living organism, secondary metabolites are slightly less vital. Secondary metabolites are synthesized by the organism and can have different functions in the organism. They can serve as a defense against predatory agents, or on the contrary attract species with beneficial effects (such as pollinators) or even allow communication between plants by sending warning signals [3].

There are three main categories of plant secondary metabolites : terpenes and terpenoids, alkaloids and phenolic compounds [4]. With 70,000 known structures [5], terpenes represent the widest family of natural compounds. They are categorized by their isoprene (five-carbon) units. As such, monoterpenes are composed of two linked isoprene units, sesquiterpenes of three, diterpenes of four, sesterpene of 5 and so on... Monoterpenes, as well as some sesquiterpenes, are highly volatiles compounds and the main constituents of essential oils [6]. They are broadly used in different fields such as fragrances in perfume industry or as flavor enhancers in food industry but their use as natural drugs has drawn the attention of many researchers and pharmaceutical industries [7]. Due to the diversity of their chemical structures, monoterpenes have shown a wide variety of biological activities such as antioxidant [8], anti-inflammatory [9], antibacterial [10], anticonvulsant [11], antinociceptive [12]... The biological activity of a product is closely linked to its concentration, thus to be able to evaluate precisely the concentration of the potential bioactive compound in an extract the extraction and analytical steps should not be neglected.

The conventional methods used for the extraction of terpenes in natural products include maceration, Soxhlet extraction, percolation and solvent extraction [7]. These processes involve long and complicated extraction period, low yield and large volume of hazardous organic solvents. In the search of making sample preparation "greener", microextraction techniques have emerged. These methods have high sensitivity, require low volumes of solvents, can even be solventless, are simple to use, low cost and amenable to automation. Different microextraction techniques have been applied for the determination of volatile chemicals in plants such as solid phase microextraction (SPME), stir bar sorptive extraction (SBSE), single drop microextraction (SDME), hollow fiber liquid phase microextraction (HFLPME) and dispersive liquid liquid microextraction (DLLME) [13]. To enhance the sensitivity towards volatiles compounds, headspace microextraction techniques can be implemented without any sample pretreatment process. Headspace single drop microextraction (HS-SDME) was first introduced by Theis et al. in 2001 [14]. In HS-SDME, a solvent drop of a few microliters is suspended at the tip of a microsyringe needle and exposed to the headspace of a sample. The sample is heated, the target compounds volatilized and adsorbed on the solvent drop. After extraction, the suspended drop is retracted back into the microsyringe and analyzed most often by gas chromatography. This method is fast, simple, inexpensive and requires only microliters of solvents. One of the most important parameter of HS-SDME is the choice of the extracting solvent. The later should answer to essential criteria to ensure the stability of the drop: low volatility, low vapor pressure, thermal stability and enough viscosity. The most common solvents used for SDME such as toluene, hexane, isooctane, decane, $n$-octyl alcohol are toxic for the environment and often have nonnegligible volatility which can cause the evaporation of the drop [15]. First ionic liquids (ILs) have emerged as an alternative to organic solvents in HS-SDME due to their low vapor pressure [16]. However, concerns about the application of ILs for the extraction of bioactive 
compounds have arisen due to the toxicity of these solvents, their potential effects on health and environment, and the high cost associated with their synthesis and purification requirements [17].

To overcome the limitations of ILs, deep eutectic solvents (DESs) have emerged. A DES is usually composed of a mixture consisting of a hydrogen bond acceptor (HBA) with a hydrogen bond donor (HBD). Those two compounds are mixed at a precise molar ratio called a eutectic point at which, simply by heating, they form a new solvent liquid at room temperature. The first DES was introduced by Abbot et al. and was made of choline chloride and urea at a molar ratio of 1:2 [18]. DESs have similar solvent characteristics to ILs but are cheaper to produce due to the low costs of raw materials, less toxic and often biodegradable. In addition to being ecofriendly, physicochemical properties of DESs are easily tunable by changing one of the two components of the system. An unlimited number of combinations exist to form DESs allowing them to have a wide range of applications. They have been used as dissolution solvents, catalysis solvents, in organic synthesis, in electrochemistry, in the preparation of nanoparticles and as extraction solvents [19]. DESs have been used for the extraction of bioactive compounds by different extraction techniques such as microwaveassisted extraction, ultrasonic-assisted extraction, heating-stirring extraction, liquid-liquid extraction [17]. However, DESs have rarely been used for HS-SDME [20] or for the extraction of terpenes [21-23] and only once for the extraction of terpenoids by HS-SDME to our knowledge [24].

Based on the discussion in the text above, the aim of the present study was to develop a robust and efficient extraction method for terpenes by coupling novel green solvents (DESs) to a well-known extraction method sensitive to volatiles compounds (HS-SDME). To conduct this study, the development of the extraction method was done spices, model of plant rich in terpenes. DES-HS-SDME was first optimized by design of experiments and then applied to six spices (cinnamon, cumin, fennel, clove, thyme and nutmeg) to evaluate the efficiency of the method for the extraction of terpenes from plants. Qualitative and quantitative analysis based on 29 standards were conducted for each extract.

\section{Experimental}

2.1.Chemicals and materials

Tetrabutylammonium bromide $\left(\mathrm{N}_{4444}-\mathrm{Br}, \geq 99 \%\right)$, decanol $(\geq 99 \%)$, $\beta$-citronellol $(\geq$ $95 \%)$, anethole $(\geq 98 \%)$ and $\alpha$-terpineol $(\geq 97 \%)$ were purchased from Fluka (Buchs, Switzerland). Butanol $(\geq 99.5 \%)$ and ethanol $(\geq 99.8 \%)$ were purchased from Fisher Scientific (Illkirch-Graffenstaden, France). Methanol (99.9\%) was obtained from Carlo Erba (Val-de-Reuil, France). Methyltrioctylammonium chloride $\left(\mathrm{N}_{8881}-\mathrm{Cl}, \geq 97 \%\right)$, octanol $(99.3$ $\%$ ), dodecanol ( $\geq 98 \%$ ), hexanoic acid $(99-100 \%)$, lactic acid ( $\geq 85 \%)$, choline chloride $(\geq$ $98 \%$ ), urea ( $\geq 99.5 \%)$, $\alpha$-pinene (99\%), $\beta$-pinene (99\%), camphene $(95 \%)$, p-cymene (99 $\%)$, 3-carene ( $\geq 90 \%)$, linalool (97\%), limonene (97\%), pulegone (97\%), 4-terpineol ( $\geq 95$ $\%)$, caryophyllene ( $\geq 98.5 \%)$, menthone $(97 \%)$, camphor $(96 \%)$, menthol $(99 \%)$, borneol ( $\geq 99 \%$ ), estragole (98\%), $\alpha$-humulene (96\%), farnesene (mixture of isomers), eucalyptol $(99 \%)$, cuminaldehyde (98\%), eugenol (99\%), carvacrol (98\%), menthyl acetate (97\%) and thymol $(98 \%)$ were purchased from Sigma-Aldrich (Steinheim, Germany). Geraniol (98\%) was purchased from Carl Roth GmbH (Karlsruhe, Germany).

Cinnamon (Cinnamomum zeylanicum, Chamsyl), thyme (Thymus vulgaris, Chamsyl), cumin (Cuminum cyminum, Conquête des saveurs), fennel (Foeniculum vulgare, Ducros), clove (Syzygium aromaticum, Ducros) and nutmeg (Myristica fragrans, Ducros) were all bought from a local shop. Spices were obtained as fine-grained powders, except for fennel which was seeds, and thyme which was cut in small pieces. All food samples were used as bought; no additional grinding was done. 


\subsection{Preparation of deep eutectic solvents (DESs)}

The synthesis of DESs was adapted from Tang et al. [25]. Briefly, two components, a hydrogen-bond donor (HBD) and a hydrogen-bond acceptor (HBA), were weighed according to their appropriate molar ratio and put in a closed glass vessel. To form the DES, the mixture of HBD and HBA was heated at $80{ }^{\circ} \mathrm{C}$ under constant stirring until a homogeneous liquid was formed (approximatively 2 hours). With 3 different HBAs and 7 HBDs, ten combinations of DESs (table 1) were prepared.

\subsection{Headspace single drop microextraction (HS-SDME) procedure}

Fifty milligrams of sample were weighed in a $20 \mathrm{~mL}$ headspace vial $(23 \mathrm{x} 75 \mathrm{~mm})$ which was closed with PTFE-lined silicon septa and metallic screw caps. The needle of a 10 $\mu \mathrm{L}$ GC microsyringe (10R, SGE Analytical Science Pty Ltd, Australia) containing $2 \mu \mathrm{L}$ of DES was introduced in the headspace of the sample vial through the septum. The volume of DES was then pushed down the microsyringe to form a drop at the tip of the needle. The vial with the microsyringe was placed in an incubator at $80{ }^{\circ} \mathrm{C}$ during $90 \mathrm{~min}$ allowing the absorption of the volatile compounds on the DES drop. Once the extraction process was completed, the drop was withdrawn into the microsyringe, disposed in a $250 \mu \mathrm{L}$ insert $(29 \mathrm{x}$ $5.7 \mathrm{~mm}$ ) placed in a $2 \mathrm{~mL}$ vial and weighed. To prevent the analytical instruments from damages, the drop was diluted in ethanol and spiked with an internal standard prior to injection in GC-MS. The microsyringe was washed 4 times with ethanol and 2 times with the extraction DES before each extraction.

\subsection{Optimization of DES-HS-SDME conditions by design of experiments}

A design of experiments approach was used to optimize the different parameters of DES-HS-SDME. This approach allows to identify which parameters have a significant influence on the response, if there are interactions between the parameters and to find the optimal extraction conditions. The response was defined as the area of the peak of the corresponding compound: one peak corresponds to one response. To optimize the extraction conditions for a maximum of compounds, 27 different characteristic terpenes in nutmeg (figure 1) were used as responses. This way, the influence of the extraction parameters on 27 different compounds will be analyzed by the design of experiments approach. The 27 compounds all have different chemical properties, such as polarities and boiling points. The aim is to find optimal conditions which are a compromise of the optimal conditions for each individual terpene found in nutmeg. For data manipulation, JMP ${ }^{\circledR}$ Statistical Discovery ${ }^{\mathrm{TM}} 8$ (SAS Institute) was used.

First, for the screening of the influential parameters, a $2^{4}$ full factorial design was built. The number of experiments required for this design was equal to $19\left(2^{4}+\right.$ three central points). The data obtained from those experiments were fitted according to the following equation corresponding to a second order model [26]:

$$
y_{i}=\beta_{0}+\beta_{1} x_{1}+\beta_{2} x_{2}+\beta_{3} x_{3}+\beta_{4} x_{4}+\beta_{12} x_{1} x_{2}+\beta_{13} x_{1} x_{3}+\beta_{14} x_{1} x_{4}+
$$

$\beta_{23} x_{2} x_{3}+\beta_{24} x_{2} x_{4}+\beta_{34} x_{3} x_{4}+\varepsilon$

where $y$ is the response (the area of a selected peak), $x_{i}$ the studied parameters, $\beta_{0}$ the constant, $\beta_{i}$ the coefficients of the parameters, $\beta_{i j}$ the coefficients of the interaction parameters and $\varepsilon$ the experimental error.

The aim of this first design is to calculate the significance of the coefficient of each factor on the response.

Then, choosing only the significant parameters, a $2^{2}$ faced centered design was used to determine the optimal extraction conditions for each response. The number of experiments required for this design was equal to $11: 2^{2}=4$ points corresponding to the full factorial design 
+3 central points +4 points on each face of the experimental domain corresponding to a square for a $2^{2}$ design. The data obtained from those experiments were fitted according to the following equation, adding quadratic terms to the previous equation for the determination of the optimum conditions [26]:

$$
y_{i}=\beta_{0}+\beta_{1} x_{1}+\beta_{2} x_{2}+\beta_{12} x_{1} x_{2}+\beta_{11} x_{1}^{2}+\beta_{22} x_{2}^{2}+\varepsilon
$$

where $\beta_{i i}$ represents the coefficients of the quadratic parameters.

With this design, for each response, optimal extraction conditions were obtained, i.e. 27 slightly different optimal extraction conditions were obtained. To find optimal conditions which are a compromise for all 27 responses, the desirability function approach was used [27]. This method consists of first drawing desirability functions $(d)$ for each response. The desirability is defined as such : $d=0$, lowest desirability obtained for the lowest peak area; $d=1$, highest desirability obtained for the highest peak area. Then an overall desirability function $(D)$ is drawn from the partial desirability functions obtained for each compound. Optimal extraction conditions are found when the overall desirability is maximized, the aim being maximizing the peak area of each compound (corresponding to maximizing the extraction efficiency).

The experimental data was fitted by least squares. To validate the adequacy of the model's design to fit the experimental data, three values were evaluated. Model's explained variations $R^{2} \geq 0.8$ and predicted variations $Q^{2} \geq 0.5$ showed an acceptable fitting of the data [28]. The values of $Q^{2}$ are not needed for the screening design as the aim of this design is not to predict the responses but they are calculated for the face centered design for which the aim is to predict the optimal conditions for the responses. The lack of fit $(\mathrm{LoF})$ of the model was calculated by comparing the model error to the experimental error by an $F$-test. The statistical significance of the coefficients of the extraction parameters $\left(\beta_{\mathrm{i}}, \beta_{\mathrm{ij}}\right.$ and $\left.\beta_{\mathrm{ii}}\right)$ were estimated using an analysis of variance (ANOVA) with a $95 \%$ confidence level.

\subsection{Gas chromatography-mass spectrometer (GC-MS) conditions}

GC-MS analyses were conducted on a 450-GC/240-MS (Varian, Les Ulis, France) GC-MS system. Two microliters of the extract was injected in a split/splitless injector at 210 ${ }^{\circ} \mathrm{C}$. The compounds were then carried on a DB-WAX capillary column $(60 \mathrm{~m} \mathrm{x} 0.25 \mathrm{~mm} \times$ $0.15 \mu \mathrm{m}$ ) (Agilent Technologies, Les Ulis, France) by helium (purity 99.9999\%) at 1 $\mathrm{mL} / \mathrm{min}$. They were separated along the column according to the following heating program : $1 \mathrm{~min}$ at $40^{\circ} \mathrm{C}$, increased to $100^{\circ} \mathrm{C}$ at $10^{\circ} \mathrm{C} / \mathrm{min}$, heated to $130^{\circ} \mathrm{C}$ at $5^{\circ} \mathrm{C} / \mathrm{min}$, heated to $150^{\circ} \mathrm{C}$ at $10^{\circ} \mathrm{C} / \mathrm{min}$, heated to $180^{\circ} \mathrm{C}$ at $5^{\circ} \mathrm{C} / \mathrm{min}$, heated to $230^{\circ} \mathrm{C}$ at $10^{\circ} \mathrm{C} / \mathrm{min}$ and then held isothermal at $230^{\circ} \mathrm{C}$ for $5 \mathrm{~min}$. For the MS parameters, the transfer line was set at $200{ }^{\circ} \mathrm{C}$ and the ion source at $150{ }^{\circ} \mathrm{C}$. The electron multiplier was set to $70 \mathrm{eV}$. The mass spectra were recorded in a full scan mode in the range of $50-200 \mathrm{~m} / \mathrm{z}$. Peaks were identified by referring mass spectra to the NIST mass spectral database considering a match factor higher than $800 \mathrm{a}$ good match. The identification was then confirmed by calculating the retention index (RI) of each compound and comparing it to the literature for DB-WAX type columns.

\subsection{Quantification of terpenes in spices}

Quantification of terpenes in the extracts was carried out by using 29 standards (figure 2). For each compound, calibration curves were drawn with 10 points in two concentration ranges: from $1 \mu \mathrm{g} / \mathrm{g}$ to $10 \mu \mathrm{g} / \mathrm{g}$ and from $10 \mu \mathrm{g} / \mathrm{g}$ to $500 \mu \mathrm{g} / \mathrm{g}$. Solutions were prepared in methanol. Each concentration was extracted in triplicates. For the extraction, $20 \mu \mathrm{L}$ of the standards solution was mixed with $50 \mathrm{mg}$ of inert Fontainebleau sand (previously heated at $600^{\circ} \mathrm{C}$ for 4 hours) and placed in a $20 \mathrm{~mL}$ headspace vial $(23 \times 75 \mathrm{~mm})$ which was closed with PTFE-lined silicon septa and metallic screw caps. The extraction was then carried out according to 2.3. Each standard was quantified according to the area of the compound's 
selected ion which was extracted from the TIC analysis (usually the main ion of compound's mass spectra). The limits of detection (LOD) and limits of quantification (LOQ), defined as the lowest concentrations detected at a signal-to-noise ratio of three or ten respectively, were calculated for each standard. The calibration curves were drawn above the LOQ for all standards.

\section{Results and discussion}

\subsection{Screening of DESs}

The choice of the extracting solvent is a crucial parameter in the HS-SDME extraction. In HS mode, to ensure drop stability the solvent should have low volatility, low vapor pressure and enough viscosity [15]. DESs have high thermal stability and negligible volatility [29]. With hundreds of combinations possible to obtain a DES, one can easily be tailored made to meet the physicochemical properties (such as the viscosity for example) needed for HS-SDME and its polarity can conveniently be tuned to the one of the studied compounds. 10 different DESs were tested for the extraction of terpenes in nutmeg. In this study, nutmeg was selected as a model as it is a plant rich in a wide variety of terpenes [30]. The effect of the extracting solvent on the extraction efficiency is shown in figure 3 . This figure shows the number of identified compounds in the extracts obtained with the various DESs but also the quantity extracted (relative to the peak area) for 27 characteristic terpenes found in nutmeg. Those compounds have different polarities and boiling points, the aim is to find a DES able to extract the widest range of terpenes. DESs are composed of two components, a HBA and a HBD, changing one of them can change the physicochemical properties of the DES. The find the most efficient DES for the extraction of terpenes, different combination of DESs were tested. The influence of an increase of the alkyl chain from $\mathrm{C}_{4}$ (butanol) to $\mathrm{C}_{12}$ (dodecanol) of the HBD was studied (figure 3 (a)). The corresponding $\mathrm{HBA}$ used was $\mathrm{N}_{4444} \mathrm{Br}$. For most compounds, increasing the carbon chain from $\mathrm{C}_{4}$ (butanol) to $\mathrm{C}_{8}$ (octanol) increases the extraction efficiency. Beyond $\mathrm{C} 8$, the quantity of terpenes extracted does not increase but using a carbon chain of $\mathrm{C}_{12}$ (dodecanol) allows to extract more compounds (42) than the other HBDs studied (39 for butanol, 34 for octanol and 32 for decanol). Even though the physicochemical properties of DESs are difficult to evaluate, an increase of the carbon chain decreases probably the polarity of the solvent which is more suitable for the studied compounds according to the results. From those results, $\mathrm{N}_{4444} \mathrm{Br} / \mathrm{DoDec}$ was selected and compared to other $\mathrm{N}_{4444} \mathrm{Br}$ based DESs by changing the chemical nature of the HBD. Two other HBDs were studied: hexanoic acid and lactic acid. As lactic acid is likely to be more polar than hexanoic acid, $\mathrm{N}_{4444} \mathrm{Br} / \mathrm{LactA}$ is less adequate for the extraction of terpenes than the other two DESs tested (figure 3 (b)). For almost all studied compounds, $\mathrm{N}_{4444} \mathrm{Br} / \mathrm{hexanoic}$ acid extracts with the same extraction efficiency as $\mathrm{N}_{4444} \mathrm{Br}$ /dodecanol. However, some compounds have more affinity with dodecanol than for hexanoic acid as 36 compounds are extracted by $\mathrm{N}_{4444} \mathrm{Br} / \mathrm{HexA}$ compared to 42 by $\mathrm{N}_{4444} \mathrm{Br} / \mathrm{DoDec} . \mathrm{N}_{4444} \mathrm{Br} / \mathrm{DoDec}$ was again selected after those observations and compared to another DES by changing its HBA to $\mathrm{N}_{8881} \mathrm{Cl}$. $\mathrm{N}_{8881} \mathrm{Cl}$ seems more apolar than $\mathrm{N}_{4444} \mathrm{Br}$, however the latter extracts more compounds (42) than the first one (32) (figure 3 (c)). The extraction efficiency of $\mathrm{N}_{4444} \mathrm{Br} / \mathrm{DoDec}$ was also compared to the one of other DESs and in particular to the first synthetized [18] and most used DES [31]: choline chloride/urea (1:2). ChCl/Urea showed a very weak extraction efficiency for the studied compounds as well as $\mathrm{ChCl} / \mathrm{LacA}$ (figure 3 (d)). $\mathrm{ChCl}$ has an alkyl chain shorter than the other two HBA studied which results in a higher polarity. $\mathrm{ChCl}$ based DESs are thus not well adapted for the extraction of terpenes. $\mathrm{N}_{4444} \mathrm{Br} / \mathrm{DoDec}(1: 2)$ showed higher extraction efficiency than the other 9 DESs studied and was selected for the optimization of the DES-HS-SDME extraction parameters. 


\subsection{Optimization of DES-HS-SDME conditions by design of experiments}

3.2.1. Screening of the significant extraction conditions: $2^{4}$ full factorial design

The optimization of the extraction parameters is an essential step of developing a robust and repeatable extraction method. When dealing with solid/gas and gas/liquid equilibria, like for HS-SDME, it is necessary to have extraction parameters at which the equilibrium state is reached. In most cases, the optimization of the HS-SDME parameters is done by optimizing one-variable-at-a-time (OVAT) while holding the others fixed [32-35]. Though this approach can lead to the best extraction conditions, it does not consider the interactions between the variables. With the design of experiments approach, the optimal conditions are found with a minimal number of experiments necessary while determining the influential parameters and their potential interactions. The first step is to screen the different interaction parameters and find the influential ones. The parameters studied and their respective levels are reported in table 2. Four parameters (extraction temperature, extraction time, drop volume and sample mass) were tested at two levels $(-1 ;+1)$. Three experiments at the central point of each parameter have been carried out. A $2^{4}$ full factorial design was used. The model used to fit the data of the experiments was considered well adapted (table 3): $\mathrm{R}^{2}>0.8$ for all responses and no lack of fit was observed. The extraction temperature $(T)$ and the extraction time $\left(t_{e x t}\right)$ had a statistical positive influence on most responses (78\% of the responses for $T$ and $96 \%$ for $t_{e x t}$ ), meaning that an increase of those parameters results in an increase of the responses. The data also showed a strong correlation between $T$ and $t_{e x t}$ as the coefficient of their interaction was statistically significant for $96 \%$ of the responses, demonstrating that those two variables shouldn't be studied separately from one another. No statistically significant interactions between the other factors were observed. The increase of the drop volume from $0.5 \mu \mathrm{L}$ to $2.5 \mu \mathrm{L}$ resulted in an increase of one response ( $\alpha$-pinene) and a decrease of $34 \%$ of the responses, while the mass sample was statistically significant for only one response. Those two factors were considered non-significant for the rest of the study. To facilitate the handling of the drop, its volume was fixed at $1.5 \mu \mathrm{L}$. The sample mass was fixed at $50 \mathrm{mg}$, the lower value of the interval studied, in order to work with the lowest quantity of raw material possible. In fact, raw material can be rare or difficult to obtain, an extraction method needing few raw materials is therefore a great advantage.

\subsubsection{Finding the optimum: $2^{2}$ face centered design}

For the determination of the optimal extraction conditions, a $2^{2}$ face centered design was built with only the parameters who had a statistically influence on the responses (3.2.1.): the extraction temperature $(T)$ and the extraction time $\left(t_{\text {ext }}\right)$. As observed from the previous design (3.2.1.), an increase of $T$ and $t_{e x t}$ leads to an increase of the responses. The studied intervals were therefore increased to find the optimum settings, table 4 resumes the levels chosen for each factor. The model used to fit the data obtained from the experiments was considered well adapted: values of $\mathrm{R}^{2}>0.8$ were obtained for all responses but one (4-terpineol acetate), values of $\mathrm{Q}^{2}>0.5$ were obtained for $93 \%$ of the responses and no lack of fit was observed for any of the responses (table 5). $t_{\text {ext }}$ was found not statistically significant in this interval as an increase of $t_{\text {ext }}$ from $60 \mathrm{~min}$ to $120 \mathrm{~min}$ had a significative impact on less than half the responses $(41 \%)$. A known phenomenon was observed regarding the results obtained for $T$. An increase of this parameters led to an increase of $29 \%$ of the responses but led to a decrease of $59 \%$ of the responses. This observation is strongly linked to the physicochemical properties of the studied compounds. In table 5, the terpenes are ordered by their retention indexes which is directly related to their boiling point, i.e. $\alpha$-pinene has the lowest boiling point $\left(156{ }^{\circ} \mathrm{C}\right)$ while myristicine has the highest one $\left(277^{\circ} \mathrm{C}\right)$. The $29 \%$ of the responses (from $\alpha$-terpineol to myristicine) which were increased by an increase of the temperature are the ones with high boiling point, those compounds are volatile at higher temperatures. On the 
contrary, the $59 \%$ of the responses (from $\alpha$-pinene to 4-terpineol) which were decreased by an increase of the temperature are the ones with lowest boiling points, those compounds are volatile at lower temperatures. When an increase of temperature occurs, the gas phase will be enriched in molecules with higher boiling points in addition with the ones with low boiling points, thus more high boiling points components will absorb in the DES drop resulting in an increase of their responses. Furthermore, at high temperatures, compounds with low boiling points might have more affinity with the gas phase than with the DES drop, which leads to the decrease of their responses. This phenomenon can be associated to the back-extraction of the compounds in the headspace [36]. The optimization approach used in this study shows the necessity to consider the greatest number of responses (i.e. the greatest number of analytes) when investigating the extraction parameters. Considering only the sum of peaks or number of peaks as done in most optimization by design of experiments cases [37] is not enough to fully understand the extraction process. The second step to optimize the extraction conditions by this approach is to find an optimum which is a compromise between all the optimums for each response, i.e. for each compound studied. The use of the desirability function allows to find such an optimum. The aim was to maximize the individual desirability functions for each response and to plot an overall desirability function. The contour plot of this function is shown in figure 4 . The maximum overall desirability $(D=0.556)$ is reached at the following extraction conditions: $80^{\circ} \mathrm{C}$ for $T$ and 90 min for $t_{\text {ext }}$. The overall desirability was not equal to 1 as it is a compromise between the desirabilities of the different compounds. If all 27 responses had the same optimums, the overall desirability would have been equal to 1 .

The optimal extraction conditions selected for DES-HS-SDME were: $50 \mathrm{mg}$ sample mass, $1.5 \mu \mathrm{L}$ drop volume, $80{ }^{\circ} \mathrm{C}$ extraction temperature and 90 min extraction time.

\subsection{Calibration}

After determination of the optimal extraction parameters, calibration by DES-HSSDME coupled to GC-MS was conducted for 29 terpenes. Table 6 summarizes the results obtained for the calibration of each terpene. The values of the correlation coefficient $\left(\mathrm{R}^{2}\right)$ were above 0.99 for all studied compound, which indicates good linearity in the concentration ranges studied of the extraction method. To analyze the repeatability of the calibration, the relative standard deviation (RSD) was calculated at $10 \mu \mathrm{g} / \mathrm{g}$ for each compound $(\mathrm{n}=3)$. Most compounds showed acceptable repeatability (RSD<20\%), only three compounds (limonene, 4-terpineol and $\alpha$-farnesene) had higher RSDs. LODs and LOQs were determined for each compound. LOQs were in the ranges of 0.47 to $86.40 \mu \mathrm{g} / \mathrm{g}$. This result shows the importance of conducting a full qualitative analysis as semi-quantitative analysis is not reliable enough. Each compound, even compounds from the same chemical family, has its own affinity with the extraction method but also with the analytical method. The sensibility of the process is related to the compound's response for the analytical method, i.e. low LOQs shows high response thus high sensibilty, on the contrary, high LOQs shows low response thus low sensibility. More than half of the studied compounds had LOQs lower than $2 \mu \mathrm{g} / \mathrm{g}$, showing that DES-HS-SDME is well adapted for the extraction of terpenes.

\subsection{Application to the extraction of terpenes from spices}

The optimized DES-HS-SDME method was applied to the extraction of terpenes from six spices: cinnamon, cumin, fennel seeds, clove, thyme and nutmeg. As expected, the plant containing the most terpenes was nutmeg. 42 compounds were identified in nutmeg extract, 32 in thyme, 20 in cumin, 16 in cinnamon and in clove and only 4 in fennel seeds (figure 5). Chromatograms of each extract with their main identified components are shown in figure 5 . The main constituents identified in the extracts (regarding the \% peak area) are consistent with previous works on spices: cinnamaldehyde in cinnamon [38], cuminaldehyde in cumin 
[39], eugenol in clove [40], thymol in thyme [41] and myristicine in nutmeg [42]. The main component of fennel extract obtained by DES-HS-DES was estragole (qualitatively and quantitatively), however anethole is known to be the main compound in fennel [43]. Anethole might lack affinity with the DES used for HS-SDME. Furthermore, the boiling point of estragole $\left(216^{\circ} \mathrm{C}\right)$ is lower than the one of anethole $\left(234^{\circ} \mathrm{C}\right)$ which can explain the difference of sensibility of the extraction method between the two compounds ( $\mathrm{LOQ}_{\text {Anethole }}=1.70 \mu \mathrm{g} / \mathrm{g}$ and $\mathrm{LOQ}_{\text {Estragole }}=0.75 \mu \mathrm{g} / \mathrm{g}$ ). The choice of the extraction method is an important step of analytical chemistry as the content of an extract depends heavily on the extraction method. Those first results show that the DES-HS-SDME method is well adapted for the extraction of terpenes from natural materials. Full qualitative and quantitative analysis of the different extracts are summarized in table 7. Not all identified compounds (by their mass spectra and RIs) were quantify, only the ones corresponding to the 29 standards used for the calibration (3.3.). If only a semi-qualitative analysis is conducted (relative to the percentage area of each compound), the concentration might be over or under evaluated. When comparing the relative concentration of two compounds in a same extract, the percentage areas of those compounds might not relate directly to one compound being more abundant than the other. Each compound as its own sensibility towards the extraction method, low sensibility does not necessarily mean low abundance of the compound. This is well-illustrated in the spices extracts (table 7). In the cumin extract, (E)- $\beta$-farnesene and carvacrol have almost the same abundance regarding the percentage of peak area (approximately $0.5 \%$ ) but their quantities calculated by the calibration differ by a factor of almost $20(13,640 \pm 2,062 \mu \mathrm{g} / \mathrm{g}$ for (E)- $\beta$ farnesene and $758 \pm 123 \mu \mathrm{g} / \mathrm{g}$ for carvacrol). (E)- $\beta$-farnesene is almost 20 times more abundant in cumin than carvacrol. If a semi-quantitative analysis based on the relative percentage abundance had been done, the conclusion would had been that those two components are found in cumin at approximatively the same concentration. Conducting semiquantitative analysis of different compounds using only one internal standard, relative concentrations of analytes are compared to the one of the internal standard, can also lead to false conclusions. $\alpha$-pinene and $\beta$-pinene are isomers, their chemical structures are similar. Those two compounds were found in the nutmeg extract at approximatively the same concentration $(212,672 \pm 28,137 \mu \mathrm{g} / \mathrm{g}$ for $\alpha$-pinene and 231,250 $\pm 42,013 \mu \mathrm{g} / \mathrm{g}$ for $\beta$-pinene). However, if looking at only percentage peak area, $\beta$-pinene is 6 times more abundant in nutmeg $(2.7 \%)$ than $\alpha$-pinene $(0.43 \%)$. If a compound with a chemical structure close to the ones of $\alpha$-pinene and $\beta$-pinene, such as camphene for example (figure 2), had been used as a standard to evaluate the relative concentration of $\beta$-pinene, it would have been over evaluated by a factor of 6 . The DES-HS-SDME method allows to produce extract rich in a wide range of terpenes and terpenoids. The quantitative analysis used in this study provides a wellunderstanding of the extraction and analytical method.

\section{Conclusion}

Optimal extraction conditions of DES-HS-SDME were easily determined by the use of chemometric. Full quantitative analysis of the extracts allowed a better understanding of the extraction technique and of the extracts. This study showed that DESs can be a possible alternative to organic solvent in HS-SDME for the extraction of volatiles compounds in natural samples. DES-HS-SDME is simple, cheap, rapid, made eco-friendly by the use of DESs and efficient for the extraction of terpenes from spices. DESs have an important potential in green extraction and analytical chemistry.

\section{Acknowledgements}

This work has been financially supported by "Association Nationale Recherche Technologie" with the CIFRE Contract n²016/0447. 


\section{References}

[1] D.J. Newman, G.M. Cragg, D.G.I. Kingston, Natural products as pharmaceuticals and sources for lead structures, in: Pract. Med. Chem., Second Edi, Elsevier Inc., 2003: pp. 91-109.

[2] D.J. Newman, G.M. Cragg, Natural products as sources of new drugs over the last 25 years, J. Nat. Prod. 70 (2007) 461-477. doi:10.1021/np068054v.

[3] D. Tholl, Terpene synthases and the regulation, diversity and biological roles of terpene metabolism, Curr. Opin. Plant Biol. 9 (2006) 1-8. doi:10.1016/j.pbi.2006.03.014.

[4] R. Croteau, T.M. Kutchan, N.L. Lewis, Natural products (secondary metabolites), in: Biochem. Mol. Biol. Plants, 2000: pp. 1250-1318.

[5] K. Vavitsas, M. Fabris, C.E. Vickers, Terpenoid metabolic engineering in photosynthetic microorganisms, Genes (Basel). 9 (2018) 1-19. doi:10.3390/genes9110520.

[6] R.N. De Almeida, M. De Fátima Agra, F.N.S. Maior, D.P. De Sousa, Essential oils and their constituents: Anticonvulsant activity, Molecules. 16 (2011) 2726-2742. doi:10.3390/molecules16032726.

[7] H.-J. Bart, Extraction of natural products from plants - An introduction, in: Ind. Scale Nat. Prod. Extr., 2011: pp. 1-25.

[8] A. Kozioł, A. Stryjewska, T. Librowski, K. Sałat, M. Gaweł, A. Moniczewski, S. Lochyński, An overview of the pharmacological properties and potential applications of natural monoterpenes, Mini-Reviews Med. Chem. 14 (2014) 1156-1168. doi:10.2174/1389557514666141127145820.

[9] D. V Fonsêca, P.R.R. Salgado, H. de C. Aragão Neto, A.M.F.O. Golzio, M.R.D. Caldas Filho, C.G.F. Melo, F.C. Leite, M.R. Piuvezam, L.C. de M. Pordeus, J.M. Barbosa Filho, R.N. Almeida, Ortho-eugenol exhibits anti-nociceptive and antiinflammatory activities, Int. Immunopharmacol. $38 \quad$ (2016) 402-408. doi:10.1016/j.intimp.2016.06.005.

[10] D. Trombetta, F. Castelli, M.G. Sarpietro, V. Venuti, M. Cristani, C. Daniele, A. Saija, G. Mazzanti, G. Bisignano, Mechanisms of antibacterial action of three monoterpenes, Antimicrob. Agents Chemother. 49 (2005) 2474-2478. doi:10.1128/AAC.49.6.24742478.2005 .

[11] N.F. Salakhutdinov, K.P. Volcho, O.I. Yarovaya, Monoterpenes as a renewable source of biologically active compounds, Pure Appl. Chem. 89 (2017) 1105-1117. doi:10.1515/pac-2017-0109.

[12] S. Yano, Y. Suzuki, M. Yuzurihara, Y. Kase, S. Takeda, S. Watanabe, M. Aburada, K.I. Miyamoto, Antinociceptive effect of methyleugenol on formalin-induced hyperalgesia in mice, Eur. J. Pharmacol. 553 (2006) 99-103. doi:10.1016/j.ejphar.2006.09.020.

[13] C. Yang, J. Wang, D. Li, Microextraction techniques for the determination of volatile and semivolatile organic compounds from plants: A review, Anal. Chim. Acta. 799 (2013) 8-22. doi:10.1016/j.aca.2013.07.069.

[14] A.L. Theis, A.J. Waldack, S.M. Hansen, M.A. Jeannot, Headspace solvent microextraction, Anal. Chem. 73 (2001) 5651-5654. doi:10.1021/ac015569c.

[15] W. Wardencki, J. Curyło, J. Namieśnik, Trends in solventless sample preparation techniques for environmental analysis, J. Biochem. Biophys. Methods. 70 (2007) 275288. doi:10.1016/j.jbbm.2006.07.004.

[16] K.D. Clark, M.N. Emaus, M. Varona, A.N. Bowers, J.L. Anderson, Ionic liquids: solvents and sorbents in sample preparation, J. Sep. Sci. 41 (2018) 1-416. doi:10.1002/jssc. 201700864 . 
[17] M.H. Zainal-Abidin, M. Hayyan, A. Hayyan, N.S. Jayakumar, New horizons in the extraction of bioactive compounds using deep eutectic solvents: A review, Anal. Chim. Acta. 979 (2017) 1-23. doi:10.1016/j.aca.2017.05.012.

[18] A.P. Abbott, G. Capper, D.L. Davies, R.K. Rasheed, V. Tambyrajah, Novel solvent properties of Choline Chloride Urea mixtures, Chem. Commun. (2003) 70-71. doi:10.1039/B210714G.

[19] Q. Zhang, K. De Oliveira Vigier, S. Royer, J. François, Deep eutectic solvents: syntheses, properties and applications, Chem. Soc. Rev. 41 (2012) 7108-7146. doi:10.1039/C2CS35178A.

[20] S.M. Yousefi, F. Shemirani, S.A. Ghorbanian, Enhanced headspace single drop microextraction method using deep eutectic solvent based magnetic bucky gels: Application to the determination of volatile aromatic hydrocarbons in water and urine samples, J. Sep. Sci. 41 (2018) 966-974.

[21] K.M. Jeong, Y. Jin, D.E. Yoo, S.Y. Han, E.M. Kim, J. Lee, One-step sample preparation for convenient examination of volatile monoterpenes and phenolic compounds in peppermint leaves using deep eutectic solvents, Food Chem. 251 (2018) 69-76. doi:10.1016/j.foodchem.2018.01.079.

[22] E. Su, M. Yang, J. Cao, C. Lu, J. Wang, F. Cao, Deep eutectic solvents as green media for efficient extraction of terpene trilactones from Ginkgo biloba leaves, J. Liq. Chromatogr. Relat. Technol. 40 (2017) 1-7. doi:10.1080/10826076.2017.1309661.

[23] J. Cao, L. Chen, M. Li, F. Cao, L. Zhao, E. Su, Two-phase systems developed with hydrophilic and hydrophobic deep eutectic solvents for simultaneously extracting various bioactive compounds with different polarities, Green Chem. 20 (2018) 18791886. doi:10.1039/C7GC03820H.

[24] B. Tang, W. Bi, H. Zhang, K. Ho Row, Deep Eutectic Solvent-Based HS-SME coupled with GC for the analysis of bioactive terpenoids in Chamaecyparis obtusa leaves, Chromatographia. 77 (2014) 373-377. doi:10.1007/s10337-013-2607-3.

[25] W. Tang, Y. Dai, K.H. Row, Evaluation of fatty acid/alcohol-based hydrophobic deep eutectic solvents as media for extracting antibiotics from environmental water, Anal. Bioanal. Chem. 410 (2018) 7325-7336. doi:10.1007/s00216-018-1346-6.

[26] L.V. Candioti, M.M. De Zan, M.S. Cámara, H.C. Goicoechea, Experimental design and multiple response optimization. Using the desirability function in analytical methods development, Talanta. 124 (2014) 123-138. doi:10.1016/j.talanta.2014.01.034 0039-9140.

[27] M.A. Bezerra, R.E. Santelli, E.P. Oliveira, L.S. Villar, L.A. Escaleira, Response surface methodology (RSM) as a tool for optimization in analytical chemistry, Talanta. 76 (2008) 965-977. doi:10.1016/j.talanta.2008.05.019.

[28] T. Lundstedt, E. Seifert, L. Abramo, B. Thelin, Å sa Nyström, J. Pettersen, R. Bergma, Experimental design and optimization, Chemom. Intell. Lab. Syst. 42 (1998) 3-40. doi:10.1016/S0169-7439(98)00065-3.

[29] M. Espino, M. de los Ángeles Fernández, F.J. V Gomez, M.F. Silva, Natural designer solvents for greening analytical chemistry, TrAC - Trends Anal. Chem. 76 (2016) 126136. doi:10.1016/j.trac.2015.11.006.

[30] G.I.C. Simpson, Y.A. Jackson, Comparison of the chemical composition of East Indian, Jamaican and other West Indian essential oils of Myristical fragrans Houtt., J. Essent. Oil Res. 14 (2002) 6-9. doi:10.1080/10412905.2002.9699743.

[31] B. Tang, K.H. Row, Recent developments in deep eutectic solvents in chemical sciences, Monatshefte Fur Chemie. 144 (2013) 1427-1454. doi:10.1007/s00706-0131050-3.

[32] B. Tang, M. Tian, K.H. Row, Determination of terpenoids in Chamaecyparis obtusa 
leaves by headspace single-drop microextraction with gas chromatography detection, Anal. Lett. 47 (2014) 48-57. doi:10.1080/00032719.2013.832278.

[33] V. Sawaddipanich, S. Chanthai, Headspace-single drop microextraction followed by gas chromatographic determination of key aroma compounds in tomato fruits and their sample products, Orient. J. Chem. 32 (2016) 1271-1282. doi:10.13005/ojc/320301.

[34] M. Moradi, M. Kaykhaii, A.R. Ghiasvand, S. Shadabi, A. Salehinia, Comparison of headspace solid-phase microextraction, headspace single-drop microextraction and hydrodistillation for chemical screening of volatiles in Myrtus Communis L, Phytochem. Anal. 23 (2011) 379-386. doi:10.1002/pca.1368.

[35] C. Jiang, S. Wei, X. Li, Y. Zhao, M. Shao, H. Zhang, A. Yu, Ultrasonic nebulization headspace ionic liquid-based single drop microextraction of flavour compounds in fruit juices, Talanta. 106 (2013) 237-242. doi:10.1016/j.talanta.2013.01.028.

[36] M. Jalali Heravi, H. Sereshti, Determination of essential oil components of Artemisia haussknechtii Boiss. using simultaneous hydrodistillation-static headspace liquid phase microextraction-gas chromatography mass spectrometry, J. Chromatogr. A. 1160 (2007) 81-89. doi:10.1016/j.chroma.2007.05.096.

[37] F. Sadeghian, P. Ebrahimi, A. Shakeri, M.R. Jamali, Extraction of Citrus paradisi Volatile Components by Headspace Single-Drop Microextraction and Statistical Modeling, J. Chromatogr. Sci. 54 (2016) 1263-1269. doi:10.1093/chromsci/bmw038.

[38] B. Marongiu, A. Piras, S. Porcedda, E. Tuveri, E. Sanjust, M. Meli, F. Sollai, P. Zucca, A. Rescigno, Supercritical $\mathrm{CO}_{2}$ extract of Cinnamomum zeylanicum: Chemical characterization and antityrosinase activity, J. Agric. Food Chem. 55 (2007) 1002210027. doi:10.1021/jf071938f.

[39] J. Yang, H. Wei, C. Yu, Y. Shi, H. Zhang, Extraction of the volatile and semivolatile compounds in seeds of Cuminum cyminum L. Using hydrodistillation followed by headspace-ionic liquid-based single-drop microextraction, Chromatographia. 75 (2012) 1435-1443. doi:10.1007/s10337-012-2335-0.

[40] M. Santana De Oliveira, W. Almeida Da Costa, D. Santiago Pereira, R. Santos Botelho, T. Oliveira De Alencar Menezes, E. Helena De Aguiar Andrade, S. Helena, M. Da Silva, A. Pedro, D. Silva, S. Filho, R. Nunes De Carvalho Junior, Chemical composition and phytotoxic activity of clove (Syzygium aromaticum) essential oil obtained with supercritical $\mathrm{CO}_{2}$, J. Supercrit. Fluids. 118 (2016) 185-193. doi:10.1016/j.supflu.2016.08.01.

[41] A.L. Dawidowicz, E. Rado, D. Wianowska, M. Mardarowicz, J. Gawdzik, Application of PLE for the determination of essential oil components from Thymus vulgaris L, Talanta. 76 (2008) 878-884. doi:10.1016/j.talanta.2008.04.050.

[42] A. Piras, A. Rosa, B. Marongiu, A. Atzeri, M.A. Dessì, D. Falconieri, S. Porcedda, Extraction and separation of volatile and fixed oils from seeds of myristica fragrans by supercritical $\mathrm{CO}_{2}$ : Chemical composition and cytotoxic activity on caco-2 cancer cells, J. Food Sci. 77 (2012) 1-6. doi:10.1111/j.1750-3841.2012.02618.x.

[43] W.-R. Diao, Q.-P. Hu, H. Zhang, J.-G. Xu, Chemical composition, antibacterial activity and mechanism of action of essential oil from seeds of fennel (Foeniculum vulgare Mill.), Food Control. 35 (2014) 109-116. doi:10.1016/j.foodcont.2013.06.056. 